\title{
Reflective use of video recording in class
}

\author{
Peter Ward \\ peter334moa@hotmail.com
}

Submission Type: Presentation Format (20mins + 10minsQ\&A)

Keywords: reflective video-recording, language-learning

\begin{abstract}
:
Reflective video-recording in language-learning classes is engaging, effective and fun. Practices and techniques are highly transferable to other subject areas. In developing speaking competence and confidence, language teachers are constantly assessing and balancing the need to address either accuracy and/or fluency.

Video-recording in a supportive, sensitive environment with learners and teachers who know each other well can capture spoken language and visual communication and allow it to be worked on, like words on paper, as a text for analysis, discussion and feedback in a variety of ways, both top-down and bottom-up. Accuracy can be addressed without affecting fluency as the sample of speech is recorded, not live.
\end{abstract}

The use of video-recording and play-back lends itself particularly well to a wide range of language-learning approaches and methodologies, including Community Language Learning (CLL), Dogme ELT, task-based learning (TBL) and others, under the umbrella of a communicative approach.

Classes using video-recording are spontaneous and adaptive, very learner-centred and allow for responsive and sensitive adjustment to students' needs, strengths and areas for improvement as well as cultural and linguistic considerations.

This case study will include edited video extracts of a video of a mock speaking test being analysed by a class of learners who are all engaged in practising for this this style of test. They share feedback in a supportive, affirming atmosphere. There is a high level of engagement and interaction.

The video of this class, in turn, is shown to a group of teachers, who use it as a text to workshop ideas for delivering feedback and generating learner-led discussion for meaningful alternative authentic self-assessment. The teachers also discuss the use of technology-enhanced learning in regard to this use of video.

Another layer of video shows a professional development session with a wider body of teachers leading into discussion on using video in professional development of teachers and teacher-trainers.

This case-study session will involve explanation of the methodology and pragmatics of this simple way of using video, recorded with students' and teachers' phones in class to enhance reflective learning with a range of clips of the various layers. 